\section{Taxonomy across the language barrier}

\section{C.A. Stace}

Grasses of the Soviet Union, in two volumes.

By N.N. Tsvelev. Translated by

B.R. Sharma.

Oxonian Press, New Delhi (distributed by A.A. Balkema, PO Box 1675,

Rotterdam, Netherlands): 1984.

Pp.1,196. Dfl.145, \$50, £34.

THOSE who doubt that language is still one of the world's greatest barriers should scan the references in a range of scientific papers written in different languages, when the bias towards the mother tongue will soon become obvious. While English-speakers are often able to get the gist of papers written in most European languages, the huge fund of scientific information written in Russian and Japanese (inter alia) is out of the reach of the vast majority of Western scientists.

The programme of translations of scientific works in these two languages (and others) being carried out by the Oxonian Press in India is therefore a notable service to the academic community. About 200 books have been translated, mostly in the past ten years and mostly from Russian, on disciplines ranging widely in the sciences
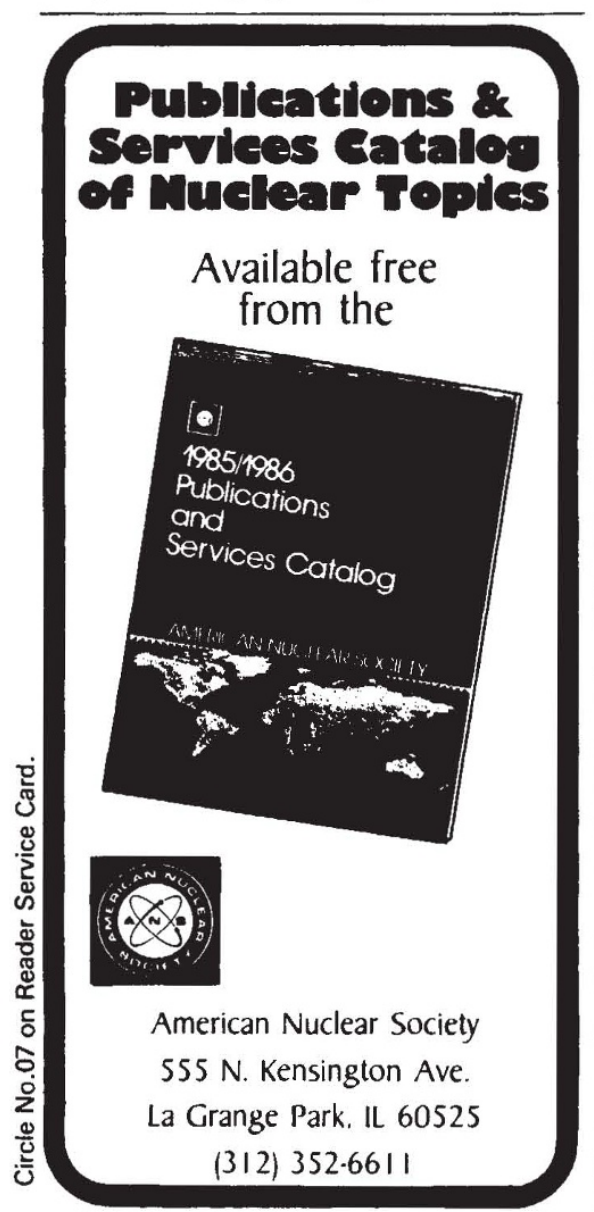

but with an emphasis on biology and on agriculture. The work reviewed here is a translation of N.N. Tsvelev's Poaceae U.R.S.S. of 1976, itself effectively an updating of the classic second volume (Gramineae) of Flora U.R.S.S. published in 1934.

Grasses are, without doubt, the most important group of organisms as far as mankind is concerned. The development of cereals can be said to have constituted the birth of agriculture and to have signalled the development of civilization, and today grasses are still the staple food of most races of man and of the animals he keeps for food. Our continued welfare depends upon improved methods of grass utilization, including the exploitation of new kinds of grass. A detailed knowledge of the grass flora of the USSR, said to number 1,011 species (compared with 880 in Europe, including European Russia), is therefore vital.

The first 67 pages of the present work are taken up with an essay on the structure and supposed evolutionary trends of grasses, followed by a map and detailed list of the phytogeographical divisions of the USSR. The most important part of Tsvelev's monograph is, however, the systematic treatment, which occupies 1,004 pages. In it, a key to genera and keys to species and subspecies within each genus are provided, as is a detailed classification of subfamilies, tribes, subtribes and various infra-generic ranks. Each of the taxa at the ranks from subfamily to generic section is provided with an extended diagnosis, but there are no descriptions of species or lower taxa for these one has to rely on the information in the keys. Under each species there are full nomenclatural and distributional details, chromosome numbers (including some previously unpublished counts), and frequently a valuable discussion of unusual variants or taxonomic problems.

Because of generous spacing and reasonably good quality paper, Grasses of the Soviet Union is produced in two volumes each of which is roughly the same size as the complete Russian work. It resembles the translations of Flora U.R.S.S. carried out by the Israel Programme for Scientific Translations in that the Russian page-numbers are placed in the margin, and the index entries all refer to them. In the contents pages, however, entries refer to the English-version pagenumbers, a quirk to which users will soon become accustomed. The printing is clear and the binding seems to be adequate.

This work is literally essential to any serious grass taxonomist or breeder, and will remain a standard reference work for many decades. Agrostologists the world over are indebted to the publishers for making this authoritative masterpiece available more widely.

C.A. Stace is Reader in Plant Taxonomy and Head of the Department of Botany at the University of Leicester.

\section{The daily Aztec}

\section{Warwick Bray}

The Aztecs. By Brian M. Fagan.

W.H. Freeman: 1984. Pp.322. Hbk

$\$ 27.95, £ 26.95$; pbk \$14.95, £13.95.

IN THE 1950s, when Brian Fagan and I were students together, he was about to become an Africanist and I was still a European prehistorian. Since then, each of us has written a popular book on the Aztecs, his having just been published.

Although separated by 16 years, there is more than a passing resemblance between the two studies, not only in format, but also in the illustrations and in the choice of quotations from sixteenth-century sources. This is some indication of the continuing importance of the rare eyewitness accounts left by those who took part in the conquest of Mexico (Hernando Cortes and Bernal Diaz) and by the missionary friars (Sahagún, Motolinía and Durán) who followed closely behind. Since there are at least two other "daily life" books in circulation, and using the same basic sources, one should not take too much notice of the publisher's claim that the present work is unique. As the most recent of its genre it is, however, the most up to date.

Professor Fagan has established a solid, and well-deserved, reputation as an archaeological popularizer who can be relied on to say the right things in a lively and comprehensible style. He has done so again. Little of what he tells us is new, but, like a good journalist, he has mastered the readily available literature and has checked his facts with the experts. He has also avoided the temptation, which afflicts so many writers on the Aztecs, of overemphasizing the spectacular or the horrific - the gold, temples and human sacrifices - at the expense of the more mundane aspects of daily existence. The end product is a trustworthy and well-balanced introduction to Aztec history and customs, very much in the tradition of descriptive ethnography. Whatever can be seen or can be readily comprehended, whether it is physical (clothing, buildings, farming tools and so on) or behavioural (warfare, marriage, worship) is accurately summarized.

What I found to be missing, though it would perhaps frighten off the nonspecialist reader, is analysis of the meaning behind the picture: the nature of the Aztec economy, the philosophical ideas behind the poetry and the religious ceremonies, the principles underlying Aztec law and so on. Instead, the book presents an observer's view - what you would see if you were there - and does it very well. This, probably, is as much as most people want. But it does not add up to the "definitive book" promised by the publisher's blurb.

Warwick Bray is Reader in Latin American Archaeology at the University of London. 